\title{
«APRENDAN EL VOSOTROS PARA HABLAR CON LOS ESPAÑOLES EN SU IDIOMA»: LA IDENTIFICACIÓN LINGÜÍSTICA EN ARGENTINA COMO TENSIÓN ENTRE EL ORGULLO Y LA MINUSVALORACIÓN
}

\author{
"Learn the vosotros [you conjugation] to speak with Spaniards in \\ their language»: Linguistic identification in Argentina as a tension \\ between pride and underestimation
}

\section{María López García*}

Fecha de recepción: 10/03/2015 Fecha de aceptación: 06/04/2014

Resumen. El trabajo analiza la construcción de una identidad lingüística a través de los manuales escolares argentinos. La hipótesis de base es que la escuela argentina sobrelleva el imaginario decimonónico que le dio lugar como organismo de difusión de saberes y creación de la ciudadanía, pero en la actualidad los instrumentos que utiliza para la enseñanza y las leyes que gobiernan el funcionamiento de estos materiales están fuertemente influenciadas por las reglas del mercado. Por lo tanto, la lengua española, portadora de la herencia hispánica como pauta aglutinante en la escuela argentina del siglo XIX, se desprovee en la actualidad de los límites territoriales (y, con ello, de las marcas de la variedad lingüística) porque, al trascenderlos, puede adecuarse a las pautas expansionistas del mercado. En el marco de la glotopolítica y apoyándose en las teorías que estudian el lugar de las emociones en los procesos de auto-identificación, el artículo analiza la coexistencia entre una identificación lingüística «globalizada» y una identificación dialectal. Esta tensión genera identificaciones de signo contrario en los ciudadanos/hablantes en tanto la práctica lingüística escolar se asocia a la pertenencia a la nación, pero al mismo tiempo desalienta las marcas de lo nacional a través del uso de manuales globalizados. El análisis de rasgos lingüísticos regionales en una muestra de libros escolares (algunos actuales y otros correspondientes a hitos históricos en la enseñanza argentina) permitirá mostrar las identidades superpuestas generadas discursivamente entre una lengua desterritorializada y una pauta curricular que fomenta la valoración de las variedades.

\footnotetext{
* Consejo Nacional de Investigaciones Científicas y Técnicas (CONICET) - Universidad de Buenos Aires. Centro Argentino de Estudios Históricos «Claudio Sánchez Albornoz». M.T. de Alvear 1694 (1060). Buenos Aires. Argentina.maguilopezgarcia@yahoo.com.ar
}

Cómo citar este artículo: López García, María. «"Aprendan el vosotros para hablar con los españoles en su idioma”: la identificación lingüística en Argentina como tensión entre el orgullo y la minusvaloración», Historia y Memoria de la Educación, 2 (2015): 97-124. 
Palabras clave: Emociones e identidad nacional. Identidad lingüística. Variedades del español. Glotopolítica. Enseñanza de la lengua.

Abstract. This paper analyses the construction of a linguistic identity in Argentina through school textbooks. The basic assumption is that the Argentinean school continues to exhibit the $19^{\text {th }}$ century imaginary of being the agency for the diffusion of knowledge and the construction of citizenship, but that today, the instruments that it employs for teaching and the laws that govern the functioning of these materials are strongly influenced by the rules of the market economy. Therefore, the Spanish language, bearer of the Hispanic heritage and a binding element of the Argentinean school of the $19^{\text {th }}$ century, is no longer subject to territorial limits (and thus, to the particularities of linguistic variety) because, by moving beyond these limits, language is able to more easily adapt itself to the expansionist tendencies of the market. In the framework of linguistics politics and relying on the theories that study the role of emotions in the process of self-identification, the article analyses the coexistence of "globalized" language and dialect identification. The tension between these two aspects of language generates identifications of contrasting natures among citizens/speakers; on the one hand, linguistic practice in school is associated with belonging to the nation, while at the same time the use of global textbooks and manuals tends to inhibit the use of language featuring particular local or national elements. The analysis of regional linguistic features in a sample of textbooks (from the present and from past milestones in Argentina) evidences overlapping identities discursively generated between a de-territorialized language and a curricular pattern that promotes the appreciation of varieties.

Keywords: Emotions and national identity. Linguistic identity. Spanish varieties. Glotopolitics. Language teaching.

\section{INTRODUCCIÓN}

Cuando la señorita Fabiana comprobó que todos los chicos de $5 .^{\circ}$ grado habían completado el cuadro de conjugaciones verbales dejando vacío el espacio de la segunda plural peninsular, los alentó: «es importante que aprendan el vosotros, así, si se encuentran con un español, pueden hablar con él en su idioma».

Al parecer, los argentinos hablamos otra cosa que el español. En una encuesta tomada por investigadores de la Universidad de Buenos Aires hace 15 años a hablantes rioplatenses, ${ }^{1}$ los encuestados decían hablar «lunfar-

${ }^{1}$ Para indagar las características de la encuesta tomada en el año 2000 a 360 hablantes de Buenos
Aires, y conocer los resultados parciales, véase Leonor Acuña y José Luis Moure, «La gramática en 
do», «argentinismo», «argentino vulgar», «castellano impuro», «una especie de castellano», y, al mismo tiempo señalaban «el verdadero idioma es el argentino, que es nuestro», "deseo que con el tiempo tengamos un idioma propio». Esta compleja configuración de sentimientos acerca de la propia lengua y, con ella, de la pertenencia a un colectivo regional fue tomando forma a lo largo de los dos siglos que lleva la historia institucional argentina y los 130 años de sistema educativo formal.

Este trabajo se propone mostrar el modo en que se han ido construyendo en la Argentina (con especial atención a Buenos Aires) las formas de identificación lingüística, partiendo de la base de que la identidad cultural de la nación se funda sobre discursos, entre ellos, los discursos acerca de la lengua que se habla.

Para analizar el conglomerado de factores que confluyen en la generación de sentimientos sobre la lengua regional, tomamos la idea de que los hablantes del español de la Argentina (en sus diferentes variedades) inscriben su identificación dialectal en una tensión. Por un lado, advertimos un sentimiento de orgullo, que se registra desde los discursos independentistas de 1837 en los que se valora la diferencia que la variedad argentina representa respecto de la lengua española peninsular modélica. Por otro, notamos un sentimiento de inferioridad, surgido de la exposición a instituciones de la lengua que señala(ba)n las diferencias regionales como deformaciones respecto de una lengua común.

La primera parte del trabajo se aboca a rastrear las huellas de esos sentimientos hacia la lengua puestos en tensión. El recorrido de la sección inicial atraviesa más de un siglo de historia de la lengua española en la Argentina, deteniéndose en los hitos más representativos en relación con las discusiones político lingüísticas. Este apartado acude a ejemplos tomados de manuales escolares de los períodos mencionados y a legislación lingüístico-educativa. Ambos géneros permiten ilustrar las afirmaciones que se formulan bajo la premisa de que ha sido (y es) la escuela la institución encargada de moldear la identidad lingüística argentina.

una encuesta sobre actitudes lingüísticas», ponencia inédita presentada al Congreso Internacional $L a$ Gramática: modelos, enseñanza, historia. Instituto de Lingüística, Universidad de Buenos Aires; y María López García, «No sos vos, soy yo: la identidad lingüística argentina como conflicto», en Lengua, historia y sociedad, ed. D. Lauria y M. Glozman (Buenos Aires: Sociedad Argentina de Lingüística, 2013). http://ffyl1.uncu.edu.ar/spip.php?article3830 (consultado el 14/05/2015). 
La segunda parte del trabajo busca mostrar que el resultado de esta tensión entre el sentimiento de orgullo y de inseguridad lingüística que acompaña a los hablantes los convierte en sujetos pasivos ante el control lingüístico operado por las instituciones (escuela, academias de la lengua, medios de comunicación). La hipótesis de esta segunda parte es que, en la actualidad, las leyes que gobiernan el funcionamiento de estos materiales están fuertemente influenciadas por las reglas del mercado. Por lo tanto, la lengua española, portadora de la herencia hispánica como pauta aglutinante de la escuela argentina del siglo XIX, se desprovee en la actualidad de los límites territoriales (y, con ello, de las marcas de la variedad lingüística) porque, al trascenderlos, puede adecuarse a las pautas expansionistas del mercado.

Para demostrar esta afirmación, se analizan algunos ejemplos de manuales de lengua pasados y actuales. Los ejemplos posteriores al año 1993 son representativos de un corpus mayor estudiado con detalle en otro trabajo. $^{2}$ En estos materiales se ponen de manifiesto dos recursos clave en la aparición (o elusión) de marcas de la variedad lingüística regional: los pronombres de las consignas, y las definiciones de los conceptos de lengua y variedad lingüística.

La metodología aplicada a estos instrumentos de enseñanza proviene del análisis crítico del discurso (Fairclough, ${ }^{3}$ Hodge y $\mathrm{Kress}^{4}$ ), y se enmarca en los estudios glotopolíticos (Guespin y Marcellesi, ${ }^{5}$ Arnoux y del Valle ${ }^{6}$ ), que abordan los hechos del lenguaje en los que la acción de la sociedad (y de las instituciones que la regulan) toman la forma de lo político. Estos marcos de análisis lingüístico se complementan con los modelos que estudian el lugar de las emociones en los procesos de autoidentificación (Scheff, ${ }^{7}$ Damasio ${ }^{8}$ ) con el fin de ahondar en la coexistencia entre una identificación lingüística globalizada y una pertenencia dialectal.

\footnotetext{
${ }^{2}$ Cfr. María López García, Nosotros, vosotros, ellos. La variedad rioplatense en los manuales escolares (Buenos Aires: Miño y Dávila, 2015).

${ }^{3}$ Norman Fairclough, Critical Discourse Analysis (London: Longman, 1995).

${ }^{4}$ Robert Hodge y Gunther Kress, Language and Control (London: Routledge and Keegan Paul, 1979).

5 Jean-Baptiste Marcellesi y Louis Guespin, «Pour la Glottopolitique», Langage, 83, (1986): 5-34.

${ }^{6}$ Elvira Arnoux y José del Valle, «Las representaciones ideológicas del lenguaje: discurso glotopolítico y panhispanismo», Spanish in Context VII (1), (2010): 1-24.

7 Thomas Scheff, Microsociology. Discourse, emotion and social structure (Chicago: University of Chicago Press, 1990).

${ }^{8}$ Antonio Damasio, En busca de Spinoza. Neurobiología de la emoción y los sentimientos (Barcelona: Crítica, 2003).
} 


\section{CONFIGURACIÓN DE SENTIMIENTOS HACIA LA LENGUA EN LA ARGENTINA: RECORRIDO HISTÓRICO}

\section{La herencia hispánica como fuente de marcas de nacionalidad}

El grupo de jóvenes intelectuales argentinos reunidos en 1837 en el Salón Literario se propuso generar un ideario que acompañara la reciente revolución independentista del 25 de mayo de $1810 .{ }^{9} \mathrm{El}$ posicionamiento en relación a la lengua extranjera de la generación del 37 se opuso al de sus antecesores en tanto promovió el contacto y liberó el uso nacional del español convirtiéndolo en rioplatense. Aferrarse a un español modélico, sostenido mediante convenciones gramaticales, representaba para ellos la sujeción a los contenidos colonizantes vehiculados por esa lengua, por eso la práctica de la contaminación lingüística es, para esta generación, la condición para el progreso de las ideas. Pero, aunque el reclamo de potestad para regular la versión nacional de la lengua española estaba asociado al programa político que continuaba el impulso independizador, no alcanzaba a las variedades «indeseadas» ${ }^{10}$ del español, ni a las lenguas del territorio. Es decir que el orgullo por el español propio sostenía el ideario nacionalista europeizante.

En los discursos iniciales sobre la construcción de la nación argentina se solaparon distintas tradiciones nacionalistas. ${ }^{11}$ Es posible distinguir, no

\footnotetext{
${ }^{9}$ Estos jóvenes intelectuales, nacidos en el período revolucionario de 1810, fundaron hacia 1837 el Salón Literario. Las reuniones persiguieron la finalidad de estudiar la implantación de las instituciones y diseñar el ideario que identificaría la incipiente nación. Los trabajos enmarcados en la historia de las ideas lingüísticas, por su parte, coinciden en ubicar en ese mismo momento histórico el comienzo de la discusión sobre la lengua nacional. A fines de 1837 buena parte de sus integrantes fueron obligados a emigrar. Así, a partir de ese momento la discusión sobre las marcas distintivas de la incipiente nación, especialmente la polémica acerca de la lengua nacional, recibió los aportes de los integrantes de aquel Salón, pero desde el extranjero.

${ }^{10}$ El habla de los argentinos ha recibido acusaciones de deformación desde diversas proveniencias académicas y legas, todas ellas inspiradas en el paradigma naturalista. Una de las respuestas más famosas es la que da Borges a Américo Castro y Amado Alonso, directores (españoles) del Instituto (argentino) de Filología Hispánica. «La palabra problema [en referencia a «El problema argentino de la lengua» de Amado Alonso] puede ser una insidiosa petición de principio. Hablar del «problema judío» es postular que los judíos son un problema; es vaticinar (y recomendar) las persecuciones, la expoliación, los balazos, el degüello, el estupro y la lectura de la prosa del doctor Rosenberg. Otro demérito de los falsos problemas es el de promover soluciones que son falsas también. A Plinio (Historia natural, libro octavo) no le basta observar que los dragones atacan en verano a los elefantes: aventura la hipótesis de que lo hacen para beberles toda la sangre que, como nadie ignora, es muy fría. Al Doctor Castro (La peculiaridad lingüística, etcétera), no le basta observar un "desbarajuste" lingüístico en Buenos Aires: aventura la hipótesis del "lunfardismo" y de la "mística gauchofilia"». Jorge Luis Borges, "Las alarmas del doctor Castro», El lenguaje de Buenos Aires (Buenos Aires: Emecé, 1998 [1941]), 34.

${ }^{11}$ La definición clásica de Herder asocia la idea de nación a una comunidad que se mantiene cohesionada por medio de una lengua. Ese sentimiento de identificación generado por la homogeneidad lingüís-
} 
obstante, diversas posturas dentro de esta generación intelectual, a las que Mercedes Blanco organiza en dos actitudes. ${ }^{12}$ Por un lado, encuentra en algunos representantes de este grupo una actitud purista, generada por la educación tradicional hispana, cuya preocupación se depositaría en detener el avance del disgregamiento lingüístico que la influencia de las lenguas extranjeras podía producir. La identificación hispánica se fundaba, para ese movimiento, en el sentimiento de vergüenza hacia la variedad local en tanto atentaba contra la unidad cultural.

Por el otro, Blanco encuentra una actitud emancipadora que, inspirada en concepciones románticas de la soberanía nacional e independencia lingüística, rechazaba la imposición de la variedad peninsular como herencia cultural. Para esta generación, el casticismo en la lengua era símbolo de casticismo en el pensamiento y eso, a su vez, de atraso. Emancipar la lengua sería, entonces, una herramienta para emancipar la nación. Por eso, distanciarse de la mirada académica y buscar en Francia, Alemania e Inglaterra modelos de lengua y de cultura resultaba funcional a la idea de progreso que se pretendía implantar (en los libros que adscribían a este marco político-lingüístico, los trozos selectos de literatura ejemplar eran tomados tanto de autores argentinos como extranjeros y se observaban críticamente las recomendaciones de la Real Academia Española —en adelante, RAE-). El sentimiento de identificación no se generaba en relación con el mundo hispánico, sino con las alianzas hacia el progreso.

En ambas tendencias, no obstante, la lengua española, independientemente de la institución que rigiera sus destinos, era identificada (ya que no enarbolada constitucionalmente) como la lengua del territorio, desplazando discursiva y físicamente a otras lenguas y otros habitantes. Bartolomé Mitre (presidente entre 1862-1868), citado en el libro El nene (que contó con más de 50 ediciones), confirmaba:

tica es lo que determina la pertenencia a una comunidad lingüística y cultural. Para Herder, y para la tradición alemana del siglo XVIII, la definición de nación se apoya en la existencia del genio, un espíritu del conjunto que tiene expresión en la lengua y en la cultura, que se manifiesta en la raza, es decir, se transmite con la sangre. Por su parte, la tradición francesa expresada en el programa iluminista entiende la nación como la comunidad espiritual surgida de la voluntad de hombres libres de vivir de acuerdo con reglas pactadas. La libre posibilidad de participar en el destino de un mismo grupo humano es lo que transforma el presente de los individuos en un presente común. La lengua implantada según ese modelo será entonces la lengua de la razón, la lengua que haga posible para la nación el camino hacia el progreso.

${ }_{12}$ Mercedes Isabel Blanco, "Actitudes lingüísticas en la primera mitad del siglo XIX en la Argentina», Cuadernos del Sur, 18 (1985): 131-149. 
El lenguaje hablado tiene una vida propia, que se dilata en la proporción del círculo de las ideas que se fecundan por su intermedio: las lenguas americanas, inorgánicas, inflexibles, sin abstractos, vaciadas todas en el mismo grosero molde gramatical, no eran susceptibles de desarrollo orgánico, ni podían expresar lo que los mismos que las hablaban no podían concebir. ${ }^{13}$

La puja sin solución entre ambos modelos acompañó la historia de la lengua nacional y ancló en los hablantes una particular confluencia de sentimientos aparentemente opuestos. La disputa por el control de la lengua, por un lado, echó raíces en España para el cuidado de la homogeneidad y la unidad, lo que implicó dejar en manos extranjeras la elaboración de los instrumentos de codificación y enseñanza. Paralelamente, generó espacios simbólicos de autorización de los intelectuales argentinos y americanos, y de las variedades de esos territorios.

No hay afán distanciador, sino positivista, de ser modernos a los fines alfabetizadores. [Y en nota al pie se aclara:] La Academia y los principales ortólogos españoles convienen en que la pronunciación de la x se acerca más á la de gs que á cs. No hai [sic] inconveniente pues en que los niños la pronuncien como gs. ${ }^{14}$

La coexistencia de ambos movimientos resultó, avanzado el siglo XX, en hablantes que se sentían (sienten), al mismo tiempo, orgullosos de las marcas distintivas de su variedad lingüística, en continuidad con los discursos independentistas, e inseguros en relación con otras formas del español, en consonancia con los discursos escolares acerca de la corrección lingüística y del español común.

\section{Enseñanza de la lengua en los comienzos del sistema educativo}

La escuela argentina fue la encargada de hacer de los habitantes del suelo ciudadanos argentinos. Lo hizo formalmente desde 1884, año de promulgación de la Ley de Educación Común N. 1.420 que los sumió bajo el discurso histórico, geográfico, científico y lingüístico del Estado-nación argentino.

\footnotetext{
13 Andrés Ferreyra, El nene: método ecléctico de lectura y escritura (Buenos Aires: Billetes de Banco, 1890), 7.

14 Marcos Sastre, Ortografía castellana americana (Buenos Aires, Coni, 1876), 22.
} 
Esta combinación de discursos de pertenencia fueron los conformadores modernos del sentimiento de comunidad. Ernesto Quesada, representante de la tradición hispanizante finisecular y presidente de una fallida academia de la lengua durante el cambio de siglo, señala en la Revista Nacional:

Afortunadamente, todas las naciones de América hispana no solo hablan sino que cultivan y defienden su hermosa lengua común. Pero, de hoy en adelante es preciso que se preste mayor atención, si cabe, a cuestiones tan interesantes, porque no se trata de una mera tendencia literaria, sino de un problema sociológico: de mantener la unidad suprema de la raza en países inundados por inmigración de todas procedencias, que principia por corromper, y concluirá por modificar el idioma nacional y, por ende, el alma misma de la patria. ${ }^{15}$

Mientras que el educador Pablo Pizzurno, entonces Inspector Técnico General del Ministerio de Educación, preocupado por alentar el compromiso de los docentes en su labor de conformar al ciudadano desde la escuela, y adscribiendo al modelo de nación posrevolucionario (que exaltaría también la influencia del francés y el inglés para el camino hacia el progreso), confía en las bondades del normalismo:

La educación patriótica. Instrucciones al personal docente

Es sabido que el conocimiento perfecto de la lengua que se habla en un pueblo puede ser un medio de hacer que este sea amado y de vincular entre sí a los hombres que lo habitan. [...]. Implícitamente, digo, que cuanto mejor se enseñe en la escuela nuestro idioma, más vincularemos al niño con su tierra, aún cuando no nos ocupemos expresamente de enseñarlo con propósitos patrióticos. ${ }^{16}$

\section{Sesta edición}

Contiene los parónimos, enseña el uso de las letras que en América no se pronuncian como en Castilla, y comprende las reglas de la Real Academia Española.

Empeñarse en que los niños pronuncien la $\mathrm{v}$ de distinto modo que la b, es tiempo perdido, porque el uso jeneral [sic] y constante en

\footnotetext{
15 Ernesto Quesada, «El problema de la lengua en la América española», Revista Nacional, XXVIII-XXIX, (1899): 257.

16 Pablo Pizzurno, La educación, patriótica. Instrucciones al personal docente (Buenos Aires: Ministerio de Educación, 1908), 14.
} 
Castilla lo mismo que en América es pronunciar la v como la b con ambos labios. [...] No hay afán distanciador, sino positivista, de ser modernos a los fines alfabetizadores. ${ }^{17}$

«On ne lit pas assez dans nos écoles». Rollin. ${ }^{18}$

Como se advierte en las citas, el proyecto normalista implementado con la primera ley de educación se situó en una tensión que definió al campo educativo argentino desde sus inicios como el resultado de las pujas entre diferentes sectores sociales y diferentes tradiciones lingüísticas. La tensión ocurría entre el impulso expansivo del programa ilustrador, al que subyacía la intención de ajustar a derecho a los habitantes del territorio, y una retracción de ese impulso, motivada en el temor que infundió la realidad del proceso inmigratorio (1870-1930) de una intensificación de la lucha de clases (alentada en parte por las mismas herramientas civilizatorias). Ese temor se vio reflejado, por ejemplo, en el diseño curricular: las ciencias se enmarcaban a rajatabla en el paradigma positivista (con ello, la clase patricia consolidaba las bases de una sociedad estamentada), mientras que la lengua se centró en el estudio de la gramática como estrategia de ordenamiento del comportamiento lingüístico, y en la práctica de una pronunciación hispanizante que unificara las prácticas orales y limitara las degeneraciones. ${ }^{19} \mathrm{La}$ lengua fue catalizador de un ordenamiento social establecido a partir del control de la práctica indeseada mediante el castigo.

Thomas Scheff ${ }^{20}$ sostiene que a partir de las emociones inducidas por la vía del castigo o la recompensa — desde el golpe con la varilla hasta la carita triste hay un amplio universo de formas en que los maestros transmiten e internalizan en los estudiantes los prejuicios sociales sobre las lenguasson categorizadas gradualmente las situaciones experimentadas. Según este investigador, la estructura de las situaciones, sus componentes y, especialmente, su significado son procesados en términos de nuestra narrativa personal. Es decir que, bajo la influencia de emociones sociales positivas

\footnotetext{
17 Marcos Sastre, Ortografía castellana americana (Buenos Aires: Coni, 1876), 9 y 22.

${ }^{18}$ Eduarda Rodríguez Larreta, Texto nacional de lectura (Buenos Aires: Cabaut 1901), Epígrafe.

${ }^{19}$ La relación entre la norma estándar y las instituciones reguladoras es premoderna. No obstante, en la modernidad la creación de un patrón revestido de prestigio no resultaba suficiente para naturalizar la homogeneidad lingüística de la comunidad, por lo que se hacía necesario implementar discursos que generaran cohesión ideológica nacional(ista) y fomentar instituciones capaces de diseñar y controlar la norma.

${ }^{20}$ Scheff, Microsociology, 15-17.
} 
y/o negativas (como orgullo, indignación, culpa, etc.), los sentimientos que de ellas se siguen se convierten en componentes obligados de nuestras experiencias y, consecuentemente, condicionan nuestras conductas sociales. Desde esta perspectiva, el castigo aplicado a la práctica lingüística con el fin de modelar hacia la ciudadanía «deseada» asocia las variedades regionales con la vergüenza y la culpa, pero, al mismo tiempo, las hace rasgo de identidad y permite asociarlas al orgullo independentista. Entendemos que es la coexistencia de ambos sentimientos lo que conformó y conforma las emociones sociales hacia las variedades regionales en la Argentina.

\section{La gramática como control social ante el aluvión inmigratorio ${ }^{21}$}

Como se ha señalado, buena parte de las reacciones nacionalistas de la elite de fines de siglo XIX tiene su explicación en el rápido ascenso social de los inmigrantes y, fundamentalmente, las consecuentes posibilidades de participación política. La incorporación del inmigrante al sistema escolar fue el principal argumento para instalar el cuidado de la lengua como rasgo constitutivo de la nación y alentar la homogeneidad de las prácticas lingüísticas. Ernesto Quesada en la Revista Nacional señala entre las causas del «menoscabo de la unidad de la lengua»:

[...] el empleo, casi general en la América Española, de maestros extranjeros y de obras de texto para los estudios de enseñanza, superior sobre todo, escritas en francés, inglés ó italiano, cuya influencia se deja sentir en la introducción de galicismos, anglicismos é italianismos; [...] el crecidísimo contingente de inmigración extranjera que afluye á muchos estados hispano americanos, y que en algunas ciudades importantísimas de aquel continente llega á constituir casi la mitad de la población total. ${ }^{22}$

Es interesante la posición de Quesada porque confirma la función de disciplinamiento lingüístico que se le atribuía a la escuela. Quesada ve en la corrupción del idioma una deficiencia de la enseñanza en las escuelas públicas. El factor principal de desconfianza era la inexistencia de instancias

\footnotetext{
${ }^{21}$ Según arroja el censo de la Ciudad de Buenos Aires, la población de esta ciudad en el año 1887 se componía de un 47,4\% de argentinos, 32,1\% de italianos, 9,1\% de españoles, 4,6\% de franceses, y 6,9\% de otras nacionalidades. Es decir que un $52,6 \%$ de la población de esa ciudad estaba compuesta por inmigrantes y casi la mitad de estos inmigrantes eran hablantes de lenguas extranjeras.

${ }^{22}$ Ernesto Quesada, «El problema de la lengua en la América española», 126.
} 
de producción nacional de libros y la mayoritaria presencia de maestros y libros del extranjero (Estados Unidos y Chile, fundamentalmente), los que, desde la gestión de Domingo Faustino Sarmiento como Director Nacional de Escuelas en el 1875, llevaban adelante las tareas educativas.

Las gramáticas, al calor de la mirada de la RAE, veían los cambios surgidos de la evolución de la variedad rioplatense como una degeneración de la lengua y, por lo tanto, del ser nacional. Este hecho es destacable porque la representación de la variedad como deformación de un único patrón lingüístico original se extiende hasta nuestros días, tal como lo muestran encuestas contemporáneas mencionadas más arriba, y como se advierte en los libros de enseñanza escolares actuales (de los que más adelante se verán algunos ejemplos). ${ }^{23}$

Es en este período cuando se empieza a incluir en el trabajo escolar la literatura gauchesca con las funciones de urdir una cultura patriótica vinculada con la tierra y, al mismo tiempo, asociar lo originario con lo criollo. La escuela ofrecía entonces, paralelamente a las campañas de exterminio indígena y reparto de tierras con fines productivos, una versión romántica, cernida con el tamiz literario, de la lengua de la tierra, la lengua del gaucho. Este intento tenía por objetivo homologar el pasado y las prácticas lingüísticas de referencia (deseables e indeseables), en especial frente a la influencia de los extranjeros que ya habían ingresado irremediablemente al sistema educativo.

El Consejo [Nacional de Educación], como era lógico, ha mandado suprimir aquellos cuadros [los retratos colgados en las escuelas de

\footnotetext{
${ }^{23}$ Durante el proceso de análisis y cotejo de las respuestas a la encuesta lingüística tomada hacia el año 2000 (mencionada anteriormente) a los hablantes rioplatenses, hemos advertido un punto de central importancia que se manifiesta no solo en las encuestas, sino que también se replica en los instrumentos de enseñanza escolar y en otros medios de comunicación: la inmigración también hace visibles las marcas lingüísticas silenciadas en favor de la construcción de un «nosotros» y, aún más, hace visible la coerción fundante de la homogeneidad. La violencia que se ejerce para la construcción de una identidad común surge, entonces, en las costuras de la marca lingüística y la «narrativa identitaria». Vimos en la pregunta 42, «¿Hay lugares en la Argentina o en otros países donde se habla peor que aquí?», que las respuestas evidencian el temor de ser un melting pot y no un crisol de razas: «en países limítrofes, por la mezcla de idiomas», «los extranjeros mezclan las palabras», «en México, por la mezcla de inglés y castellano», «en Paraguay porque hay mezclas con guaraní, hablan dialecto», «en las villas, porque se mezclan hablas de distintos países». Indefectiblemente, la lealtad al «nosotros» obliga al «yo» a sumirse en contradicciones (como sucede con el proceso de aculturación al que la escuela obliga a las clases bajas, o a los portadores de marcas regionales), es decir, para adaptar la lengua propia a la lengua de la nación, la variedad estándar, es preciso callar las marcas sociales, geográficas, familiares, etc. De este modo el «nosotros» anula las fuerzas de constitución histórica del «yo» y obliga a un futuro común. En ese sentido, el sentimiento de identificación con un «nosotros» es siempre resultado del ejercicio de cierta violencia.
} 
los Reyes Vittorio Emmanuelle, Humberto I, Elena y Margarita] y el uso de Cuore. Lo ha reemplazado, provisionalmente por los Recuerdos de Provincia, hasta que un concurso pueda proveerlos de otro más didáctico. ${ }^{24}$

El control escolar de la lengua (y del territorio y del relato histórico) como garantía de homogeneidad nacional coartó a los hablantes en pos de la unidad. La gramática operó como símbolo del límite de lo correcto e impactó directamente sobre el cuerpo, silenciándolo. ${ }^{25}$ Los sentimientos de inseguridad en relación con la lengua cotidiana se afianzaron en esa interacción escolar.

En los Colegios Nacionales y Escuelas Normales no será promovido ningún alumno que no revele dicción, ortografía y expresión correcta. Todo buen profesor dedicará especial atención al ejercicio oral para corregir vicios de expresión [...]. El comentario razonado de lecturas; la expresión del valor ideológico de las palabras y locuciones y el análisis de las ideas expuestas en trozos leídos por el estudiante [...] pueden ser motivos [...] de real eficacia para que estos ejercicios orales limpien el habla del alumno. ${ }^{26}$

Los libros de texto atendían a la diversidad de ese público que tenían que moldear. La pauta se plasmaba en los temas y autores de los textos literarios, así como en los variados géneros que asumía la enseñanza de la gramática. En este «appendix probi» que sigue queda en evidencia el destinatario.

\footnotetext{
${ }^{24}$ Ricardo Rojas, La restauración nacionalista (Buenos Aires: UNIPE, 2010 [1909]), 245.

${ }^{25}$ Elvira Arnoux atribuye a las gramáticas para el alumno posteriores al Centenario la función de reconvenir a los maestros en los usos orales. Esta autora entiende que los maestros debían convertirse en modelos de pronunciación castiza y señala que «El diccionario es, para este objetivo pedagógico, el instrumento que sustituye el modelo oral ausente fuera del ámbito de las aulas». Elvira Arnoux, El pensamiento ilustrado y el lenguaje (Buenos Aires: Eudeba, 2003), 85. A propósito, Antonio Damasio, en la obra citada En busca de Spinoza, explica que la fuerza de los sentimientos radica en que, para generar adhesiones a determinadas identidades, es preciso asociar comportamientos (físicos o discursivos) a la participación dentro de un determinado colectivo. Para ser argentino, por lo tanto, había que hablar el español de la escuela. Por medio del castigo se alentó el sentimiento de vergüenza hacia el habla «deformada», construyendo una identificación con la lengua deseada por la nación. Según Damasio, las emociones y sentimientos podrían incidir en la toma de decisiones, es decir que desempeñan un papel en los razonamientos. Señala que las experiencias vitales acumuladas en la memoria son activadas ante nuevos problemas y que, por lo tanto, los resultados obtenidos en previas ocasiones (medibles, por ejemplo, en términos de recompensa o castigo, que a su vez generan sentimientos de orgullo, vergüenza, placer, dolor, etc.) afectan las nuevas decisiones en relación con nuevos problemas.

${ }^{26}$ Ministerio de Justicia e Instrucción Pública, Conclusiones aprobadas en la Asamblea de profesores de castellano, historia y geografía argentinas e instrucción cívica (Buenos Aires: Colegio Mariano Moreno, 1934), 10-11.
} 
En los primeros casos, se reconviene la contaminación de las preposiciones del italiano (que emplea a en los casos semánticos de 1 a 4), en los siguientes, se advierte al hablante no nativo que podría no conocer el determinante masculino para una palabra comenzada en a y, finalmente, se adoctrina en los usos específicos de ciertos términos:

La maestrita

[...]

Un día les enseñaba a no decir disparates y les hizo escribir en sus cuadernos este deber, subrayando las palabras que generalmente no se emplean bien:

Debe decirse:

1. Entrar en la escuela.

2. Voy a la escuela.

3. Sentarse a la mesa para comer o escribir.

4. Sentarse en la silla para descansar.

5. Utilizar el alfiler.

6. Comprar en el almacén.

7. El pelo de los animales no es como el cabello de las personas.

8. No hay que llenar la taza hasta que rebalse.

9. El cuero de los animales no es como la piel de las personas.

10. El rasguño del gato es doloroso.

11. Se me pasa el dolor de muelas. ${ }^{27}$

La mirada sobre la voz del otro lo constituye simbólicamente y es allí donde no solo la lengua originaria del territorio, sino también la lengua familiar, la variedad regional, era descalificada en tanto que degradación de la forma correcta (lingüística y moral). El mecanismo de marginación institucional sumió al ámbito privado bajo las leyes de lo público. La fuerza de la prescripción alcanzó también a la variedad, situada en los márgenes.

De acuerdo con González Stephan, ${ }^{28}$ tanto las leyes como los relatos escolares, las gramáticas y los libros de lectura son instrumentos que instauran fronteras. Deslindan lo previsto, lo correcto, lo normal, de lo extranjero. En Argentina la lengua puesta en práctica fue la española. Hubo que señalar

\footnotetext{
${ }^{27}$ Delfina Schmid, Bello y útil: libro de lectura (Buenos Aires: Estrada, 1926), 37.

${ }^{28}$ Beatriz González Stephan, «Disciplinas escriturarias de la patria: constituciones, gramáticas y manuales», Revista de Investigaciones Literarias 3 (5), (1995): 19-46.
} 
al extranjero, al indio, al cabecita negra ${ }^{29}$ como el «otro» para adaptarlo o silenciarlo. ${ }^{30}$ Rápidamente los libros escolares se ocuparon de tematizar la mancha lingüística.

Los aires nacionales. De las características de raza, historia, lengua, configuración de territorio y otras tantas influencias secundarias es que sin duda, nace esta modalidad especial, tan compleja como típica que perfila, no menos que los rasgos exteriores, la manera de ser de cada pueblo. [...] Nacida tal vez con la primera y más amplia consagración de pueblo libre, inspiróse en lo que fueron, no menos que las costumbres, las tendencias, ideales y ambiciones que emergen de una gran aspiración, de todo lo esplendente e ilimitado en cuanto a una naturaleza siempre virgen y altiveces congénitas de raza. ${ }^{31}$

Salvar del caos el cuño nacional; que muere en este momento entre la policromía advenediza de los aluviones extranjeros, y fundar la serie de sus derivaciones subsiguientes y concordantes: una ciencia nacional, un arte nacional, una literatura, un comercio, una industria, una línea nacional, en fin: eso sería «hacer patria» según la benemérita y honda expresión de nuestros padres. ${ }^{32}$

\section{Gobierno de Juan Perón}

Durante el primer peronismo (1946-1955), el Estado se posicionó como capaz de arbitrar los conflictos de intereses de los diferentes sectores y se

\footnotetext{
${ }^{29}$ Cabecita negra es un término acuñado en la Argentina hacia 1940 en el contexto de grandes migraciones internas desde las provincias a la Capital Federal. Es empleado por las capas medias altas y altas para designar, a grandes rasgos, a la clase trabajadora (representada como hombre de piel y cabello oscuros).

${ }^{30}$ Lo que Scheff en Microsociology llama «comprensión intuitiva», es decir, aquello no dicho explícitamente pero que forma parte del sentido a ser interpretado y funciona como significado en determinado contexto social, pone en juego la empatía, el reconocimiento intersubjetivo. Para Scheff, quien sigue a Cooley y Goffman, los sentimientos de orgullo y vergüenza son primarios en el sentido de que confirman la existencia de lazos de relación en tanto reportan el éxito o el fracaso en los vínculos que el individuo establece con la sociedad. La indudablemente pregnante participación de los inmigrantes en la lengua nacional tuvo impacto en el sentimiento de inseguridad en tanto el inmigrante deformó la variedad con comportamientos lingüísticos «vergonzantes». Las encuestas más recientes corroboran este sentimiento en relación a las interferencias lingüísticas causadas por los extranjeros: [hablan mal porque] «mezclan palabras del guaraní y español», «usan lenguaje de su lugar», "no se adaptan al idioma», "deforman permanentemente el idioma» y la que más patentemente expresó la relación entre lengua y pertenencia al colectivo «hablan mal porque no tienen nacionalidad».

${ }^{31}$ Gustavo Lenns, Patria y belleza (Buenos Aires: Guillermo Kraft, 1922), 49-50.

32 José Berrutti, Lecturas morales é instructivas... (Buenos Aires: Estrada, ca. 1935), 290.
} 
filió al pasado de Mayo, instaurando una ruptura con el pasado inmediato. La fundación de lo nacional se planteó como una continuidad con la revolución independentista, aunque esta vez los grupos en oposición eran otros. Estos esquemas de oposición se reflejan en el plano lingüístico. Varios estudios ${ }^{33}$ identifican en una primera etapa el uso de la defensa de las lenguas indígenas, entendidas como rasgo autóctono, como estrategia para cimentar la identidad cultural de la nación. Mientras, paralelamente, se implementaba una política lingüística tendiente a depositar en la herencia hispánica el valor aglutinante de la lengua y a dotar a esa variedad del atributo de pureza (argumento académico sobre el que se monta - aún en la actualidad— la garantía de homogeneidad lingüística).

La escuela del período sería la encargada de consolidar este modelo doble operando como canal de difusión de la tradición católica e hispánica superpuesta con una representación de lo nacional en clave folclórica. El programa político lingüístico del peronismo, anclado en la dicotomía de la defensa de la tradición hispánica, y la valoración de las lenguas originarias y las marcas de lo popular, acude al mismo mito unificador:

Se fomentará el conocimiento amplio del idioma que nos fuera legado por la Madre Patria y de los elementos de milenaria civilización que intervinieron en su formación: el conocimiento también de sus deformaciones a fin de poder mantener la pureza de la lengua. Incluso en lo que tiene de evolución propia y formación nacional. ${ }^{34}$

En concordancia con la tradición hispana, lengua y religión fueron las columnas que sostuvieron en el primer peronismo la homogeneidad de la cultura nacional.

La cruz y la espada realizaron la conquista de América. La cruz, para enseñar las verdades de Cristo a los indios, que vivían adorando al sol, al rayo o al trueno, y que derramaban inútilmente sangre de sus hermanos. [...] España sembró en América el valor de sus soldados

\footnotetext{
${ }_{33}$ Cfr. los artículos de Mara Glozman, (2007) «Las lenguas en el primer Plan de Gobierno de Juan D. Perón: diversidad lingüística y construcción de la unidad», en Actas de las Cuartas Jornadas Internacionales de Educación Lingüística (Concordia: Universidad Nacional de Entre Ríos, 2007), y «La tradición hispanista en los discursos gubernamentales argentinos: continuidades y desplazamientos (1931-1949)», en Actas del III Congreso Internacional Transformaciones culturales. Debates de la teoría, la crítica y la lingüística (Buenos Aires: Facultad de Filosofía y Letras/UBA, 2008).

${ }^{34}$ Ministerio de Justicia e Instrucción Pública, Plan de Gobierno, Primer Plan Quinquenal (Buenos Aires, Argentina, 1947), 166.
} 
y la fe cristiana, que los criollos heredaron luego. Y dejó también un tesoro, del que disfrutamos todos: el idioma castellano. ${ }^{35}$

Los programas de estudio peronistas posteriores a la reforma de 1953 exaltaban la defensa de la lengua nacional como uno de los atributos fundantes de la nación. Por otro lado, la defensa y preservación de las variedades argentinas fue parte importante del proyecto de unidad nacional, es decir que parte de las emociones vinculadas con la unidad nacional se generaron a partir de la unidad lingüística. Se retomó la figura del gaucho, capaz de sintetizar las tendencias hispanizante y nativista, y se recuperaron las manifestaciones folclóricas, estetizadas a los fines de albergar y ordenar bajo el discurso de la tierra las formas de la cultura nacional.

Más tarde, poetas cultos como Hilario Ascasubi, Estanislao del Campo y José Hernández, embellecieron los versos nativos y crearon, respectivamente las obras Santos Vega, Fausto y Martín Fierro. En las estrofas de estos poemas está el gaucho con sus aventuras, penas y alegrías: está su lenguaje, que aprendió del conquistador y deformó luego a su manera. Bien ha dicho un escritor que la poesía gauchesca es lo más nuestro que poseemos. ${ }^{36}$

Como se advirtió arriba, al tiempo que las políticas hacia las lenguas se enmarcaron en el modelo español, la pauta cultural se hibridaba con una cultura autóctona diseñada especialmente con el fin discursivo de filiar la tierra y los rasgos lingüísticos populares (previamente pulidos) con el origen. Durante el peronismo, lengua española y cultura argentina se forjaron como fenómenos complementarios, abonando el terreno que más tarde sembrarían los libros de texto de editoriales globalizadas: la diferencia entre «lengua general» $\mathrm{y}$ «dialectos regionales».

\section{El fortalecimiento del modelo neoliberal y su impacto en la identidad lingüística}

El modelo educativo de los años 70, dictadura militar mediante, tendió a reinstaurar el orden y control del comportamiento a través de la reintroducción de pautas escolares moralizantes. La fuerza política se plasmó

\footnotetext{
${ }^{35}$ Luisa García, Siembra. Libro de lectura para 3.er grado (Buenos Aires: Kapelusz, 1955), 119.

36 José Forgione, Alfarero (Buenos Aires, Kapelusz, 1958), 124.
} 
también en el control lingüístico. El marco ideológico otorgó vigencia a los viejos fundamentos académicos, de manera que la pauta nacionalista ancló en el hispanismo, el catolicismo, y las marcas de lo rural y lo popular como rasgos de lo nacional. En este marco político-lingüístico, la identificación de la lengua nacional ocurría exclusivamente en relación con las marcas regionales y se invocaba un español común ideal que venía a simbolizar la unión del cuerpo de la sociedad, el control del desvío patológico. Las metáforas aplicadas a la lengua y los casos léxicos analizados en los cuadernillos de los maestros eran parte de un engranaje discursivo que asociaba lo popular a una participación pasiva dentro de una cultura establecida, y entendía la sociedad como un cuerpo vivo que debía organizarse jerárquicamente para no enfermar y morir.

La Subsecretaría de Cultura y Educación dispuso su distribución con el fin de aumentar el adiestramiento lingüístico por parte de los alumnos, ejemplificaciones de terminaciones en -oma y modos clínicos de nombrar el cáncer [recordemos que la metáfora empleada en ese período para nombrar a la «subversión» era «cáncer de la sociedad»], definición de «anarquía» como «falta de gobierno o estado de confusión», «derecho», «legalidad». ${ }^{37}$

\section{Las nuevas leyes de educación y el rol de mercado}

El modelo económico iniciado en la dictadura de los años 70, que se extendió hasta entrado el siglo XXI, desplazó al modelo de Estado de bienestar (que, si bien todavía estaba en pie, portaba un poder incompatible con las nuevas formas de organización institucional). Esto repercutió de maneras diversas. En el caso de la enseñanza de la lengua, a partir de la reglamentación de las leyes de educación N. ${ }^{\circ} 24.195$ (del año 1993) y N. ${ }^{\circ} 26.206$ (2006) los contenidos son seleccionados y desarrollados por empresas editoriales (cuyos materiales son empleados compulsivamente por los docentes). Las empresas pasaron a controlar la generación de emociones hacia la(s) lengua(s) de la nación y, por tanto, la identidad lingüística. ${ }^{38}$

\footnotetext{
37 Ministerio de Educación de la Nación, Apuntaciones y correcciones idiomáticas (Buenos Aires, 1977), 8.

${ }^{38}$ En un trabajo reciente analizamos más de un centenar de manuales de primaria publicados entre 1993 y 2011. En ese estudio pudimos comprobar que en estos instrumentos se evita la aparición de todas las marcas morfológicas y sintácticas de la lengua regional y solo se da importancia al léxico como nota de color dialectal. Las fórmulas de tratamiento en un $70 \%$ del material es ustedes, en un bajo porcentaje persiste el $t u ́$ (en manuales de otras asignaturas el porcentaje de tuteo es considerablemente mayor). El
} 
El cuadro de pronombres personales (incluido en la amplia mayoría de los manuales de lengua a propósito de las conjugaciones verbales de los tres paradigmas regulares) es un condensado ejemplo de las estrategias masivamente difundidas por las editoriales. Desde hace alrededor de 10 años se resolvió de manera mayoritaria ${ }^{39}$ integrar los paradigmas de todas las variedades del español según el siguiente esquema:

\begin{tabular}{|l|l|l|l|}
\hline Yo & amo & Temo & parto \\
\hline Tú/Vos & amas/amás & temes/temés & partes/partís \\
\hline Usted & ama & Teme & parte \\
\hline Él/Ella & ama & Teme & parte \\
\hline Nosotros/as & amamos & tememos & partimos \\
\hline Vosotros/as & amáis & Teméis & partís \\
\hline Ustedes & aman & Temen & parten \\
\hline Ellos/as & aman & Temen & parten \\
\hline
\end{tabular}

Vemos aquí dos problemas de diferente índole. Por un lado, los libros de texto ofrecen a los alumnos, hablantes nativos del español, las conjugaciones de los verbos regulares, conjugaciones que están capacitados para generar naturalmente desde que tienen tres años de edad. Con esta operación se va mellando la seguridad lingüística de los pequeños hablantes en tanto les son explicadas y evaluadas habilidades escolares que no son tales (ningún niño mayor de cinco años falla al conjugar los verbos regulares o irregulares de su propia lengua en la vida cotidiana, sí falla cuando la maestra se los toma en el examen).

mismo tipo de relevamiento que actualmente llevamos a cabo con libros de texto posteriores a 2010 arroja resultados más alentadores en cuanto a la presencia del enunciatario en formas voseantes, no así en las otras marcas lingüísticas regionales tales como la conjugación verbal voseante, el uso de subjuntivos, caída de plural en pronombres de objeto indirecto, construcción de formas dativas mixtas como contigo/ con vos, etc. Cfr. María López García, Nosotros, vosotros, ellos.

${ }^{39}$ Aunque todavía resta un 20\% de manuales que, aún en la actualidad, inscribe solamente la opción peninsular a pesar de que sus destinatarios no emplean ni el tú, ni el vosotros. 
Por otro lado, es interesante notar que la mixtura de variedades contribuye a la confusión entre las nociones de dialecto (regional, cuya diferencia está entre tú y vos) y registro (formal e informal, cuya diferencia radica en emplear usted o vos). Además, se presenta un cuadro con ocho pronombres personales (nueve, si deslindamos tú y vos) en lugar de seis, con lo que gráficamente se atenta contra la enseñanza a través de la pauta gramatical y se colabora con la idea de que los dialectos y los registros de la lengua son parte del mismo fenómeno. Por medio de ejercicios como este, y en continuación con la práctica de todo el siglo XX, la gramática escolar enseña, fundamentalmente, que los hablantes necesitan apoyo para conocer las formas correctas de su propia lengua, y abonan la tierra para el surgimiento del sentimiento de vergüenza frente a su variedad.

Se echaba de menos una obra que permitiera resolver, con comodidad y prontitud, los miles de dudas concretas que asaltan a los hablantes en su manejo cotidiano del idioma [...] para que todo ello ocurra dentro de los moldes propios de nuestra lengua y, sobre todo, de forma unitaria en todo el ámbito hispánico. ${ }^{40}$

En esta cita (tomada de un diccionario dirigido especialmente al público americano) radica una concepción de lengua que solapa dos definiciones: la lengua como capacidad humana innata y la lengua como norma consuetudinaria, regulada por una institución. En ese solapamiento ocurre el contrasentido: el hablante, poseedor biológico del «molde», que no requiere ningún apoyo para «manejar cotidianamente su idioma», necesitaría, no obstante, recurrir a la RAE para mantenerse dentro de los márgenes del español «unitario». Esta contradicción no es tal, si se piensa que la RAE alienta en los hablantes el sentimiento de mancomunión lingüística en indisoluble vínculo con un sometimiento a las reglas lingüísticas madrileñas. El hablante está biológicamente dotado para hablar perfectamente su lengua, pero, si quiere pertenecer con pleno derecho a la comunidad de hablantes de español, deberá adaptarse a las formas que le son dadas. En este mecanismo, centenario, de sumisión a la lengua ideal, la escuela ha tenido (y tiene) la potestad del adoctrinamiento.

Este tipo de elusiones de la variedad (ya sea porque no se la trata, ya sea porque se la confunde con los usos informales) son convenientes a los

${ }^{40}$ Diccionario Panhispánico de Dudas (Madrid: Asociación de Academias de la Lengua Española, 2005), Prólogo. www.rae.es (consultado el 14/05/2015) 
efectos comerciales en tanto permiten vender materiales en territorios hablantes de distintas variedades. Los libros escolares dejan en evidencia este interés comercial en modos diversos. En adelante analizaremos dos estrategias desplegadas por los libros escolares en relación con el tratamiento de la variedad. En el primer punto, veremos la evolución histórica de los pronombres personales empleados en las consignas. En el segundo, ofrecemos algunos ejemplos del modo en que los manuales actuales definen los conceptos de lengua y variedad.

\section{Fórmulas de tratamiento como puesta en abismo de una política lingüística: la construcción de la oralidad deseada}

En tanto los libros de texto acompañan la definición social de la realidad que describen ${ }^{41}$ y la distribuyen en todo el territorio, el objeto definido en esos materiales, la lengua, se inscribe en un entramado político que refuerza o mitiga en sus hablantes emociones sociales necesarias para su inserción en determinado colectivo (o varios); el de la ciudadanía argentina, por ejemplo. ${ }^{42}$ La lengua descripta en los manuales es, por eso, una opción política.

En las últimas décadas, las condiciones materiales de las editoriales, el constante avance de los modelos pedagógicos hacia la participación activa y crítica de los alumnos, y la desprofesionalización docente fueron liberando al maestro de su rol de intermediario necesario del libro de texto escolar y permitieron apelar directamente al alumno como enunciatario. ${ }^{43}$ Este factor no es menor porque, como mostraremos nuevamente más adelante, los libros de lengua evitan la aparición de la variedad lingüística regional moldeando directamente la relación entre la lengua escolar y la lengua de

\footnotetext{
${ }^{41}$ Cfr. Emilio Castillejo Cambra, «Indicaciones sobre la investigación "Ciudadanía, identidades complejas y cultura política en los manuales escolares españoles (1978-2006)"» [documento de trabajo, 2008] http://servidormanes.uned.es/mciud/ (consultado el 14/05/2015)

42 Desde hace algunos decenios la globalización comenzó a resignificar el concepto de identidad nacional (y, con ella, de lengua) y obligó a pensar las identidades como un lugar de pertenencia circunstancial y multiforme (y no como acuñaciones históricas y definitivas). En el contexto global, la movilidad geográfica (real o virtual) de los individuos los obligó a trasponer frecuentemente fronteras lingüísticas. Las lenguas comenzaron entonces a pujar por espacios simbólicos mayores que les permitieran controlar la circulación de rasgos lingüísticos antes custodiados por los Estados-nación a través de la escuela.

43 Para ver el desarrollo de estas afirmaciones, cfr. María López García, «A rey muerto, rey puesto. El rol del docente en el manual escolar», Revista Iberoamericana de Educación (OEI), 54 (septiembre-diciembre) (2010): 203-220. http://www.rieoei.org/rie54a10.pdf (consultado el 14/05/2015).
} 
la región en la construcción identitaria de los alumnos. Entre muchísimos otros ejemplos de exclusión del docente podemos citar:

Lean el texto en voz alta siguiendo las instrucciones de la maestra o el maestro. [...] Compartan sus producciones con sus compañeros, lean los textos en voz alta y conversen entre ustedes. ¿Cómo hicieron para describir? ¿Utilizaron todos los sentidos? ${ }^{44}$

El manual se dirige directamente al alumno, aludiendo a la situación oral de la clase, pero, al hacerlo por escrito, hace de esa oralidad inscripta un parámetro de corrección. La lengua «oral» del manual no es la misma que la hablada por el alumno ni por el docente. Esta oralidad real se transforma así en una oralidad no escolar, no enseñada y, con ello, potencialmente incorrecta.

Uno de los tantos rasgos en que la lengua de una región constituye su particularidad son las fórmulas de tratamiento hacia el estudiante presentes en los manuales. En los libros de texto posteriores a 1837 y cercanos al año de promulgación de la Ley de Educación N. ${ }^{\circ} 1.420$ (1884), la puja por una pauta lingüística escolar se debatía entre la influencia francesa e inglesa y la falta de gramáticas, diccionarios y libros de enseñanza. La lengua española instauraba entonces su fuerza cohesiva. En América y algunas zonas de España el paradigma del plural recurre al ustedes para la tercera persona. No obstante la ausencia total del vosotros en América, los libros de enseñanza escolar se dirigían a los alumnos bajo esa fórmula suscribiendo al modelo de lengua que tomaba la Península como ideal de referencia, garantía de homogeneidad..$^{45}$

Copiad estas palabras, marcad con rayitas detrás de cada palabra cuántos sonidos tiene. ${ }^{46}$

${ }^{44}$ Lengua. Serie del Faro (Buenos Aires: Kapelusz/Norma, 2006), 51. http://articulo.mercadolibre.com.ar/ MLA-550750580-lengua-4-serie-el-faro-kapelusz-norma-_JM (consultado el 14/05/2015).

${ }^{45}$ Los discursos legitimadores de la RAE, acompañados por la escuela argentina (que no menciona, ni enseña, ni reflexiona sobre la variedad y sí menciona a la RAE como agente autorizado de control), instalan el discurso de la pureza como garantía de intercomunicación iberoamericana y de pervivencia de la lengua común. Los tutores de la lengua se apoyan en el discurso de la pureza como paso previo al de la homogeneidad, pero, básicamente, instauran la idea de que la pureza se protege y de que hay custodios más calificados para llevar a cabo la tarea de limpieza. Generar consenso sobre la autoridad legítima va de la mano de diseñar estrategias de selección y privilegio de unas marcas dialectales por sobre otras. La variedad codificada en gramáticas, diccionarios y ortografías será el parámetro de lo correcto.

${ }^{46}$ Emma Nicolay de Caprile, El rudimentista (Buenos Aires; Librería Rivadavia, 1889). 
Con el cambio al siglo Xx, la inmigración forzó la adopción de un modelo hispánico unificador que hiciera posible la homogeneización de las hablas y de los credos a través de la inserción en la escuela de los habitantes.

1. ${ }^{\circ}$ RECOMENDAR al personal docente de todas las escuelas dependientes del H. Consejo [Nacional de Educación], que procure empeñosamente impedir el voseo y toda inflexión verbal incorrecta.

2. ${ }^{\circ}$ RECOMENDAR a los Inspectores Seccionales y a los Visitadores que al calificar al personal hagan especial referencia al dominio del habla que muestren directores y maestros. ${ }^{47}$

El peronismo adoptó el hispanismo como fórmula de construcción de una identidad nacional que tomaba al gaucho y al indio como las formas valoradas de lo autóctono, pero lingüísticamente indeseadas para el ideal panamericano e hispano-nacionalista del período.

Mamita me enseñó a rezar. En mis oraciones, nunca olvido a Eva Perón. Nuestra Madre Espiritual.

¡Evita! Tú seguirás siendo desde el cielo, nuestra madre tutelar. Vivimos pensando en ti $!^{48}$

El espiritualismo, llevado desde la Universidad de Buenos Aires hacia las editoriales desde los años 60 inició nuevas formas de dirigirse al alumno en tanto era preciso convocarlo desde un diálogo constructivo de los contenidos. La influencia de los avances en la lingüística promovidos y difundidos desde esa institución se evidenció en la adscripción al modelo saussureano y al esquema de Jakobson. La intención de llevar a la escuela la reflexión lingüística, y la conciencia de la importancia de representar las variedades da lugar a formas pronominales diversas en las consignas. El voseo, no obstante, ocupaba un lugar estigmatizado que se reflejaba en escasísimas apariciones (provenientes de autores con independencia del medio editorial). El alumno pasó a ser un individuo, pero la interpretación editorial de esto supuso una adaptación dialectal parcial, conveniente a los intereses transnacionales, y respetuosa de los sentimientos de inferioridad que los propios ciudadanos tienen sobre la lengua que hablan.

\footnotetext{
${ }^{47}$ Academia Argentina de Letras, Boletín de la Academia Argentina de Letras II, 5/6 (1934 [2. ed.1943]), 319.

48 Graciela A. de Videla, Evita (Buenos Aires: Luis Laserre, 1953), 10-11.
} 
Busca en el diccionario el significado de las palabras que desconozcas y escribe una oración con cada una de ellas. ${ }^{49}$

Te proponemos algunos temas de investigación: Elegido el tema, deberás organizar tu trabajo. 1. Prepararás guías, seleccionando el material aportado por el maestro y por la clase. 2. Seguirás el plan cronológico, es decir, indicarás los hechos en el orden en que ocurrieron. ${ }^{50}$

Recompone y escribe las palabras que están separadas en sílabas. Guíate por el ejemplo. ${ }^{51}$

Observá, con tus compañeros de equipo, el siguiente mensaje publicitario. ¿Qué dos aspectos reconocen de él? [...] Te sugerimos ahora que, junto con tus compañeros de equipo, traten de elaborar un cartel publicitario destinado a vender un producto que les interese... Justifiquen el empleo de determinados colores. Expliquen las razones que los decidieron por cierto texto lingüístico. ${ }^{52}$

Entre los años 80 y 90 la mayor parte de los manuales de lengua optaron por el ustedes, dejando al tuteo para otras asignaturas, pero evitaron la aparición directa de la segunda persona del singular vos. Los ejemplos que siguen son las formas tuteantes predominantes en los manuales (de diversas asignaturas) a 150 años de la independencia, y a 100 de la primera ley de educación que homologaba el discurso sobre la nación y la pauta de comportamiento lingüístico que identificaría a los ciudadanos:

Para dar a conocer qué piensas o sientes a veces es suficiente un gesto tuyo o una expresión de tu rostro... Pero también es importante que vayas descubriendo que existen múltiples y variadas formas de comunicar algo a alguien. Observa bien el objeto de que has de describir para captar sus características, su función, su belleza o importancia. ${ }^{53}$

Enumera el nombre de estos animales según su tamaño. Comienza por el menor y acaba por el mayor. Después copia los nombres en el orden indicado. [...] Dibuja un cielo con luna en cuarto creciente y siete estrellas sobre una calle empedrada y con un charco. Colorea. ${ }^{54}$

\footnotetext{
49 Lengua y Habla (Buenos Aires: Santillana, 1986), 11.

50 María Hortensia Lacau y Mabel Rosetti, Lenguaje 5 (Buenos Aires: Plus Ultra, 1980), 21.

51 Voy contigo. Mi tercer libro de lectura y de trabajo (Buenos Aires: Magisterio del Río de la Plata, 1989 ), 32.

52 Palabra va, palabra viene... (Buenos Aires: Huemul, 1989), 37.

53 Lengua y comunicación (Buenos Aires: Edicial, 1990), 64.

54 Carpeta de lengua 3 (Buenos Aires: La obra, 1992), 27 y 39.
} 


\section{NOMBRAR DIALECTO A LA LENGUA COMO ESTRATEGIA DE GLOBALIZACIÓN}

En la actualidad, de acuerdo con nuestros análisis de caso, ${ }^{55}$ una mayor proporción de manuales vosea. Pero al tiempo que lo hace, explicita puntos de vista hacia la lengua nacional que contradicen la valoración de la lengua regional como institución válida para su apropiación. En esta duplicidad los manuales involucran sentimientos de orgullo y vergüenza en la categorización de la experiencia lingüística escolar. ${ }^{56}$

El alumno (y el maestro) interpretan las diferencias entre los contenidos del manual y la lengua culta de su región en función de sus propios sentimientos sobre los valores dialectales y sus usos. Los sentimientos tensionados de orgullo por lo propio e inferioridad ante el desvío, aplicados a la lectura del manual, resultan en la asociación del concepto de variedad rioplatense con el argot o repertorio léxico llamado «lunfardo». Es esta marca léxica la que los hablantes terminan por considerar como su propia variedad. ${ }^{57}$

Hasta ahora hemos visto que el lenguaje que habitualmente usamos se compone de:

- un dialecto: el castellano español [sic] que se habla en Argentina, al que se le suman los cambios de tonada o de vocabulario y/o pronunciación de cada provincia.

$[\ldots]$

- la influencia del lunfardo, especialmente si el hablante es de Buenos Aires. ${ }^{58}$

Si la escuela argentina le otorga igual preeminencia a las formas peninsulares que a las locales y evita la reflexión sobre los rasgos de la región (en

\footnotetext{
${ }^{55} \mathrm{El}$ análisis pormenorizado de un corpus de 120 manuales de lengua posteriores a la Ley N. ${ }^{\circ} 24.295$ (1993) figura en María López García, Nosotros, vosotros, ellos, 2015.

${ }^{56}$ Cfr. Scheff, Microsociology, 17.

${ }^{57}$ Las encuestas a las que hemos hecho mención en notas anteriores confirman este dato. La pregunta 28, «¿En qué idioma está hablando usted ahora?», arrojó respuestas atendibles en tanto evidencian la fuerte percepción de las diferencias al interior del español y la necesidad de darles entidad, de asignarles una categoría que las valide. Entre las respuestas a esa pregunta se destacan varias apariciones de «argentinismo», «lunfardo», «argentino vulgar», «castellano impuro», «una especie de castellano». En algunos casos, iban acompañadas de comentarios: «Debemos darle importancia de la academia del lunfardo. Las palabras españolas sacan el significado, los de Buenos Aires le dan el significado profundo», «Hablamos como cogotudos, en lunfardo, pero ese idioma no es el nuestro. El castellano no lo hablamos».
}

${ }^{58}$ Lengua y prácticas del lenguaje (Buenos Aires: Aique, 2005), 206. 
algunos casos se vosea en los pronombres, pero no se practican las formas específicas de acentuación de verbos imperativos —salí, trabajá, etc.—, ni las formas del subjuntivo —no salgás/no salgas-, o la neutralización del pronombre dativo en la duplicación le di de comer a los chicos), los sentimientos de minusvaloración serán útiles a la desprovisión de las marcas nacionales en favor de un mercado español transnacionalizado, coherente con la nueva política de implantación del español neutro, la nueva babel. La variedad en los libros de texto es entendida, al igual que en las obras de la RAE desde hace cinco siglos, como particularismos distinguibles respecto de un español general o lengua común. ${ }^{59}$

Sección Ayuda: Se llaman dialectos las variedades lingüísticas regionales. Son las que, como su nombre lo indica, se ven enriquecidas por usos propios de esa región, ya se trate de palabras, de dichos o de algunas construcciones diferentes (el voseo en el Río de la Plata). [...] Lengua estándar es la que no contiene regionalismos, luego, es la lengua general, aquella a través de la cual puede comunicarse el vasto territorio de los hablantes de una misma lengua. ${ }^{60}$

[A propósito del trabajo sobre registro formal e informal, se sugiere para el primer caso el uso de la] Lengua estándar. Se llama así al lenguaje empleado en la escuela y también en los medios de comunicación (diarios, revistas, TV y radio) [...]. Todos los hablantes del mismo idioma usan una lengua general y también una lengua regional. Por ejemplo, la palabra «niño» es común a todos los que hablamos castellano. Las palabras «pibe», «chaval» y «gurí» significan lo mismo pero se usan en distintas regiones. ${ }^{61}$

El registro estándar es empleado en los medios de comunicación. ${ }^{62}$

\footnotetext{
${ }^{59}$ Un trabajo pionero en América Latina es el de Luis Fernando Lara y su equipo del COLMEX: el Diccionario del Español de México, que, a diferencia de otras obras que solo listan los llamados «mexicanismos» (como es el caso del Diccionario de Mexicanismos preparado por la Academia Mexicana de la Lengua, correspondiente de la RAE), entiende al español de México como un sistema completo y no un listado de marcas que lo diferencian de un supuesto español común o general. Cfr. Luis Fernando Lara, «Por una redefinición de la lexicografía hispánica», Nueva Revista de Filología Hispánica, XLIV (2), (1996): 345-364. Argentina cuenta también con el Diccionario integral del español de la Argentina (Buenos Aires: Tinta Fresca, 2008). Son estos los únicos casos de diccionarios integrales en el habla hispana fuera del madrileño de la Real Academia.

${ }^{60}$ Lengua 8 (Buenos Aires: AZ, 1997), 23.

${ }^{61}$ Manual Bonaerense 5 (Buenos Aires: Aique, 1999), 142.

${ }^{62}$ Manual 5 (Buenos Aires: Kapelusz, 2001), 89.
} 
Los dialectos regionales dependen del país. Por ejemplo, en la Argentina, decimos bebé y en Bolivia, dicen guagua. Existe también un dialecto general, que se emplea en libros o periódicos de gran circulación y que es neutro. ${ }^{63}$

La lengua general permite que todos los hablantes de un idioma, español en nuestro caso, se comuniquen y entiendan. Dentro de esa lengua hay variantes regionales, diferentes tonadas, palabras o expresiones distintas; por ejemplo pibe, chango, lolo (en Chile), mita (en Paraguay), chavo (en México), botija (en Uruguay); se trata, en este caso, de lengua regional. Como ustedes habrán observado al mirar la televisión de otros países hispanohablantes o al ver una película doblada al español, en algunos casos usan el tú en situaciones en las que nosotros usamos vos, es decir, emplean el tuteo en lugar del voseo. También, esta característica marca variantes regionales. En Los distraídos, por ejemplo, se emplean palabras que actualmente no se usan: biaba, yeta, empilche; algunas, como yeta o empilche, pertenecen al lunfardo. ${ }^{64}$

En las citas se advierte rápidamente un distingo entre la «lengua general» (llamada en algunos casos «dialecto general») y las formas regionales. Estas últimas son meros repertorios léxicos (no se mencionan las marcas sintácticas, morfológicas, prosódicas, ni pragmáticas de las regiones). Pero, a diferencia de los modelos lingüísticos alentados desde los Estados-nación decimonónicos, aquí la lengua unificadora es la del mercado, la lengua de los medios masivos de comunicación.

Emilio Castillejo Cambra ${ }^{65}$ propone el concepto de «identidades superpuestas» para las distintas identidades inculcadas en función de diversos intereses y diferentes colectivos. La disolución de la fuerza cohesiva de los Estados enmarcados ahora en alianzas económicas por fuera de sus fronteras alentó la interpenetración cultural. El modelo de Estado-nación decimonónico aplicado para formar al ciudadano argentino ha dado paso a una multiplicidad de identidades coexistentes. El hablante puede ser al mismo tiempo rioplatense, latino e hispano. Las posibles contradicciones surgidas

\footnotetext{
${ }^{63}$ Lengua y prácticas del lenguaje (Buenos Aires: Aique, 2008), 160.

${ }^{64}$ Lengua. Serie del Faro (Buenos Aires: Kapelusz/Norma, 2006).

${ }^{65}$ Emilio Castillejo Cambra, «Indicaciones sobre la investigación "Ciudadanía, identidades complejas y cultura política en los manuales escolares españoles (1978-2006)”».
} 
en el individuo sujeto de la manipulación discursiva que apela a sus diferentes pertenencias no son percibidas como tales. En el caso de la lengua, el sujeto argentino construye sus emociones vinculadas con su pertenencia a la ciudadanía en tanto que hablante regional, hablante escolar, hablante hispano, consumidor del lenguaje de los medios de comunicación (entre muchas otras identificaciones posibles). En el entramado de sentimientos asociados a esa pertenencia múltiple radica la complejidad del fenómeno de la identidad lingüística.

\section{CONCLUSIONES}

El curriculum escolar es, de algún modo, la carta de intención de un ideal de nación, de identidad nacional (por ende: ideal de cultura, de historia, de lengua). La interpretación que los libros escolares hacen de esos lineamientos ponen en conflicto el conglomerado de intereses del ámbito político-educativo y, como se advierte en el caso actual argentino, el de los grupos económicos-editoriales.

Los sentimientos convocados (en nuestro estudio, acerca de la variedad regional) por esos textos tendrán alcance en todo el territorio y conformarán el acervo de los hablantes. En el caso argentino la identidad lingüística nacional se ha ido construyendo a través de materiales que desestimaron lo regional en función de distintos objetivos políticos, en el marco de diferentes coyunturas sociales. Paralelamente, las discusiones académicas sobre la lengua nacional y su trasposición al ámbito educativo han convalidado un sentimiento de orgullo de la diferencia, de resistencia a través de las marcas de la variedad.

En este contexto, las decisiones editoriales actuales repercuten en la identidad lingüística regional porque inscriben ahora no solo en la escuela, sino también en los medios de comunicación, la forma de una lengua distinta de la(s) lengua(s) hablada(s) y escrita(s) en la nación. Los hablantes del español argentino, formados durante centenios en la minusvalía respecto del español peninsular, son ahora objeto de minusvalía frente a una lengua neutra, mito de homogeneidad y comunicación. La lengua de la región, entonces, deja de ser marca de identidad es objeto de un borramiento que la subsume a la pauta transnacionalizada. La identidad del hablante no será ya la del ciudadano, sino la del consumidor. Las estrategias desplegadas por los libros de texto para activar sentimientos de inseguridad lingüística 
son funcionales a las políticas de expansión del español global y a la pauta lingüística transnacional elaborada alternativa o combinadamente entre la Real Academia Española (o sus sucedáneos) y los medios masivos de comunicación. Antes los argentinos hablábamos mal porque estábamos lejos de España, ahora hablamos mal porque no hablamos como en la televisión.

\section{Nota sobre la autora:}

MARÍA LóPEZ García es doctora en Lingüística por la Universidad de Buenos Aires y especialista en Procesos de Lectura y Escritura por la Cátedra Unesco-Latinoamérica. Actualmente se desempeña como docente en la Universidad de Buenos Aires y como investigadora del Consejo Nacional de Investigaciones Científicas y Técnicas (CONICET), donde estudia las representaciones de la lengua en la Argentina y las políticas de enseñanza de la lengua española en la escuela. Ha participado en proyectos de investigación en el Instituto de Lingüística (UBA) y el Instituto Nacional de Antropología y Pensamiento Latinoamericano, y realizó estadías de investigación en el Lateinamerikazentrum (Technische Universität-Dresden); Institut für Romanistik (Humboldt Universität zu Berlin); Centro de Investigación MANES (UNED, Madrid) y el Ibero-Amerikanisches Institut (Berlín). En los últimos años ha dirigido diversos proyectos de investigación sobre la lengua argentina y actualmente codirige un proyecto financiado por la Agencia Nacional de Promoción Científica y Tecnológica sobre ideologías lingüísticas en la prensa escrita. 